\title{
Sobre la alteridad y la diferencia sexual
}

\section{On alterity and sexual difference}

\author{
Olaya FERNÁNDEZ GUERRERO
}

(UNED)

Recibido: 01/09/2011

Aceptado: 15/11/2011

\section{Resumen}

Este trabajo parte de la noción filosófica de alteridad, que se puede complementar con las aportaciones de la teoría feminista y su reflexión sobre la diferencia sexual.

Hay, al menos, tres aspectos del pensamiento feminista que interesa destacar a propósito de la alteridad: en primer lugar, la crítica a la construcción de lo femenino como alteridad con respecto a lo masculino; en segundo lugar, y de la mano del feminismo de la diferencia, es interesante reflexionar sobre las experiencias físicas y simbólicas de la maternidad, que proporcionan un nuevo modelo de 'alteridad irreductible' y nuevos contenidos para una ética del cuidado; en tercer lugar, y partiendo de las consideraciones de Ricoeur sobre la dialéctica entre identidad y mismidad, la alteridad sexual puede ser reformulada como una construcción dinámica articulada a partir de la tensión entre las dimensiones discursivas y performativas.

Palabras clave: Alteridad, diferencia sexual, ética del cuidado, filosofía, identidad, ontología, teoría feminista.

\begin{abstract}
This paper takes into account the philosophical issue of alterity, enriched by feminist theory and its reflection on sexual difference.

There are, at least, three aspects of feminist theory which are related to alterity: on the first hand, the critique on construction of femininity as alterity against masculinity; secondly, and together with feminism of difference, it is interesting to think about physical and symbolic experiences of motherhood, which provide a new model of 'irreducible alterity' and new contents for a Care Ethics; third, and considering Ricoeur's dialectics between idem-identity and ipse-identity, sexual
\end{abstract}


identity can be redefined as a dialogical and dynamic process concerning discursive and performative dimensions.

Keywords: Alterity, Care Ethics, Feminist Theory, Identity, Ontology, Philosophy, Sexual difference.

\section{Introducción}

Este estudio toma como punto de partida la noción filosófica de alteridad, desarrollada en el ámbito contemporáneo por Levinas, Ricoeur o Buber, entre otros. La reflexión sobre las condiciones y posibilidades de la relación con el Otro es crucial para entender buena parte de los desarrollos de la metafísica, la ética y la filosofía política de las últimas décadas, y ofrece asimismo un marco conceptual muy adecuado para abordar el pensamiento de la alteridad sexual.

La tesis principal que aquí se defiende es que el concepto filosófico de alteridad se puede complementar y ampliar con las aportaciones de la teoría feminista contemporánea, que ha prestado especial atención a una modalidad concreta de alteridad: la diferencia sexual. En las páginas que siguen se revisan las conexiones entre la teoría feminista y la filosofía de la alteridad para mostrar cómo ambos enfoques pueden complementarse, al menos en tres aspectos.

En primer lugar, tras una breve contextualización de los principales desarrollos de la filosofía de la alteridad, se hace referencia a la crítica a la construcción de lo femenino como alteridad con respecto a lo masculino, que ha servido como argumento ideológico para legitimar la subordinación de las mujeres. Simone de Beauvoir fue la primera en constatar este hecho, al afirmar que en la cultura patriarcal lo femenino ha sido tematizado como 'lo Otro' de lo masculino; después de ella, otras voces críticas han insistido en la necesidad de revisar esta construcción opresiva de la identidad femenina y sustituirla por otros modelos más tolerantes y flexibles.

En segundo lugar, y de la mano del feminismo de la diferencia, es interesante reflexionar sobre la gestación y la experiencia física y simbólica de la maternidad, que proporciona un modelo alternativo de 'alteridad irreductible' y otros paradigmas desde los que abordar la relación con el otro en términos éticos -por ejemplo, a partir del principio de cuidado-. Luisa Muraro o Luce Irigaray, entre otras, se han ocupado de estas cuestiones y han establecido un fructífero diálogo con los diferentes planteamientos filosóficos sobre la alteridad.

Por último, y partiendo de las consideraciones de Ricoeur sobre la dialéctica entre mismidad e ipseidad, la diferencia sexual puede redefinirse como una construcción dialéctica en la que entran en juego las dimensiones discursivas y poiéticas y donde confluyen diferentes planos de alteridad. Judith Butler o Rosi Braidotti han 
resaltado ese carácter construido de toda identidad sexual, en un esfuerzo por superar las lecturas esencialistas de lo 'masculino' y lo 'femenino'.

Este estudio se cierra con un apartado de conclusiones que sintetiza algunas de las principales aportaciones de la teoría feminista a la filosofía de la alteridad.

\section{La filosofía de la alteridad en el contexto contemporáneo}

El pensamiento de la alteridad, que se presenta como una alternativa a la reflexión sobre la unidad y la identidad que ha estado en el núcleo de la filosofía desde sus orígenes griegos -recordemos, por ejemplo, el monismo de Parménides-, adquiere protagonismo en el contexto contemporáneo a partir de la obra de Buber, Ricoeur y, especialmente, de Levinas, quien realiza la formulación más completa y compleja de la 'alteridad' como categoría filosófica. ${ }^{1}$ Estos autores, insertos en la tradición hermenéutica, dan origen a una corriente de pensamiento basada en la noción de 'diferencia', que se aplica a la reflexión sobre distintos ámbitos de lo humano y ofrece nuevas perspectivas para abordar fenómenos como la multiculturalidad, la diferencia sexual o las relaciones con el entorno natural.

Buber introduce una distinción entre la relación con las cosas, que siempre es de posesión, y la relación con el otro -con el 'Tú', según su terminología-, que se establece en términos diferentes y se plasma de modo específico en el lenguaje: "La palabra básica Yo-Tú funda el mundo de la relación"2 y abre un espacio para el encuentro inmediato y recíproco: "La relación significa ser elegido y elegir, pasión y acción unitariamente", 3 de tal modo que el Yo influye en el Tú al mismo tiempo que es afectado por él, en una conexión que es caracterizada como pura espontaneidad previa a todo sistema conceptual: "Toda mediación es un obstáculo. Sólo donde toda mediación se ha desmoronado acontece el encuentro". ${ }^{4}$ Además, y esto es particularmente importante para el desarrollo de la filosofía de la alteridad, se afirma que "yo llego a ser Yo en el Tú; al llegar a ser Yo, digo Tú". 5 Aquí se explicita la idea de que la identidad se construye a través de la alteridad; precisamente el hecho de ser capaz de interpelar al otro, de decir 'Tú' a quien se sitúa ante mí, es la prueba de que yo me auto-percibo como un Yo, y por tanto me dirijo a otro que es 'no-

\footnotetext{
$1 \mathrm{Si}$ bien podemos encontrar precedentes de este planteamiento de la alteridad en otros filósofos de épocas anteriores; pensemos por ejemplo en la pluralidad ontológica que ya se percibe en la Metafísica de Aristóteles, o en la apertura a la relación con otros cuerpos que Spinoza promueve en su Ética.

2 Buber, M.: Yo y tú, Madrid, Caparrós, 1995, p. 9.

3 Ibid., p. 13. En este planteamiento se hace evidente la deuda de Buber con Spinoza.

${ }^{4}$ Ibid., p. 13. Se percibe la conexión de esta tesis de Buber con la noción husserliana de 'mundo de la vida' como ámbito de experiencia inmediata y fuente de un conocimiento precategorial que es condición de posibilidad del pensamiento reflexivo.
}

5 Buber, M.: op. cit., p. 13. 
yo', pero no abordándolo como cosa entre las cosas sino articulando esa apertura desde una perspectiva ética: me dirijo al 'Tú' como otro que no es yo pero al que, sin embargo, percibo como mi semejante, es otro 'como yo'; ambos compartimos un lenguaje común que me permite interpelar al 'Tú' y que, correlativamente, posibilita que éste me pueda interpelar a mí.

Sin embargo, y según la crítica que Levinas realiza a Buber, "el Yo-Tú es acontecimiento, choque, comprensión, pero no permite explicar [...] una vía distinta a la amistad". 6 La relación Yo-Tú, descrita por Buber en términos de reciprocidad e interpelación, le parece insuficiente para dar cuenta de todas las modalidades de relación posible entre el yo y la alteridad. Partiendo de este punto, la obra de Levinas supone un intento de explicar de un modo más matizado esa relación. Considera que la filosofía occidental ha supuesto "una reducción de lo Otro al Mismo", 7 y la consecuencia de esta aproximación ha sido que todo conocimiento se ha explicado en términos de comprehensión, ha intentado abarcar el ser homogeneizándolo: "Conocer viene a ser aprehender el ser a partir de nada o llevarlo a la nada, quitarle su alteridad". ${ }^{8}$ Desde Parménides hasta Heidegger, el pensamiento ha estado marcado por una 'primacía del Mismo' que ha cancelado la posibilidad de que emerja la diferencia, y que en la práctica ha supuesto "la reducción de lo Otro al mismo". ${ }^{9}$ El problema es que esa búsqueda incesante de la unidad y la identidad "no respeta la alteridad del otro"10 sino que la subsume y somete al criterio de lo Uno, considerado ontológicamente superior.

Para reformular la alteridad como lo radicalmente Otro, inasequible a todas las categorías de unidad e identidad que intentan neutralizarla, Levinas recurre a la idea de lo infinito, en tanto que "en la idea de lo infinito se piensa lo que permanece siempre exterior al pensamiento", y también "porque el infinito desborda el pensamiento que lo piensa". 11 Esta noción de infinitud proporciona el fundamento para pergeñar una definición de alteridad entendida como 'heterogeneidad radical de lo Otro', que "sólo es posible si lo Otro es otro con relación a un término cuya esencia es permanecer en el punto de partida, servir de entrada a la relación, ser el Mismo no relativamente, sino absolutamente". ${ }^{12}$ Lo Otro se contrapone a lo Mismo,

\footnotetext{
${ }^{6}$ Levinas, E.: Totalidad e infinito. Ensayo sobre la exterioridad, Salamanca, Sígueme, 1999, p. 92.

7 Ibid., p. 67.

8 Ibid., p. 68. Levinas identifica el origen de este modelo de conocimiento en la mayéutica socrática, que instaura la 'primacía del Mismo' al asumir que en todo proceso de aprendizaje no se recibe nada del Otro, sino que únicamente se saca 'a la luz' lo que está en mí. Cfs. Levinas, op. cit., p. 67.

9 Ibid., p. 69.

10 Reyes Pedraza, J.: "La alteridad en Emmanuel Levinas", en J. Martínez Contreras y L. Ponce de León (coords.), El saber filosófico. Sociedad y ciencia, México, Siglo XXI, 2007, (pp. 159-167), p. 161.

11 Levinas, E.: op. cit., p. 51.

12 Ibid., p. 60.
} 
y esa dualidad arraiga en el plano ontológico; Levinas atribuye a la alteridad una esencia que consiste precisamente en esa inconmensurabilidad, esa exterioridad absoluta de lo Otro con respecto al Mismo que hace que lo Otro se nos presente siempre como inagotable e inabarcable en su totalidad -de ahí el recurso a la noción de infinito para explicar el modo de ser de la alteridad-.

De acuerdo con este planteamiento "la alteridad se significa en el darse lo Infinito al Mismo", 13 pero sin perder de vista que ambas categorías son esencialmente diferentes y que el encuentro a través de ese 'darse' surge siempre desde una postura inicial de separación radical. "Lo Otro metafísico es [...] una alteridad anterior a toda iniciativa, a todo imperialismo del Mismo"; 14 queda así salvaguardada su irreductibilidad ontológica.

Partiendo de esta dualidad, Levinas especifica el modo en que lo Mismo puede acceder a captar lo Otro sin cancelar su alteridad en ese movimiento: "pensar lo infinito, lo trascendente, lo extraño, no es pues pensar un objeto"15 sino que lo Otro, la alteridad, se presenta en primera instancia como 'rostro': "La noción de rostro [...] significa la anterioridad filosófica del ente sobre el ser, una exterioridad que no recurre al poder ni a la posesión". ${ }^{16}$ El encuentro con la alteridad del Otro, plasmada en el rostro que se sitúa ante mí, viene marcado por unas pautas diferentes en las que no intento someter al otro ni neutralizarlo, sino que adopto ante él una actitud ética: "recibir al Otro es cuestionar mi libertad". ${ }^{17}$ Capto al Otro como una alteridad irreductible que se sitúa frente a mí y que no puedo controlar ni poseer, y ante la que sólo cabe aceptar su libertad como contrapuesta a mi libertad: el otro "no es mi posible, no depende de mi libertad, sino que es el límite de ésta", 18 dirá Sartre.

Para Levinas, el modelo paradigmático de relación con la alteridad es el encuentro con la feminidad: "el recibimiento del rostro [...] se produce, de un modo original, en la dulzura del rostro femenino". ${ }^{19}$ Busca los modos en que el sujeto "pueda

13 Quesada Talavera, B.: “Aproximación al concepto de 'alteridad' en Lévinas. Propedéutica de una nueva ética como filosofía primera", en Investigaciones fenomenológicas, volumen 3 monográfico Fenomenología y política, 2011, (pp. 393-405), p. 394.

$<$ http://www.uned.es/dpto_fim/invfen/Inv_Fen_Extra_3/25_QUESADA.pdf $>$ [Consulta: 12 jul. 2011].

14 Levinas, E.: op. cit., p. 62.

15 Ibid., p. 73.

16 Ibid., p. 75.

17 Ibid., p. 108.

18 Sartre, J.-P.: El ser y la nada, Madrid, Alianza, 1984, p. 290. En contraposición a Levinas, Sartre tiene una concepción negativa del encuentro con el otro, ya que según su lectura el otro es un lastre para el desarrollo de la trascendencia, entendida como proyecto personal que el individuo elige por medio de su libertad.

19 Levinas, E.: op. cit., p. 169. Posteriormente volveremos sobre la conexión que Levinas establece entre la alteridad y lo femenino, y revisaremos las críticas y alabanzas de la teoría feminista a sus planteamientos. 
entrar en relación con la alteridad sin asimilarla",20 y considera que el ámbito de lo erótico es un contexto privilegiado para que aflore ese tipo de relación: "propone la sexualidad como ejemplo paradigmático de esta relación práxica donde el 'yo' se encuentra con el otro (a)" 21 y donde el elemento de conexión entre el 'amante' y la 'amada' -y no viceversa- es la caricia. Es importante señalar que, según este planteamiento, es el sujeto masculino el que toma siempre la iniciativa de la relación con la alteridad, identificada con el polo femenino de la dualidad sexual. Asimismo, el paradigma de encuentro erótico que maneja Levinas se ciñe estrictamente al modelo heterosexual constituido por la pareja hombre-mujer, obviando así la amplia gama de posibilidades de erotismo derivadas de las distintas preferencias sexuales que de hecho se dan.

Además de teorizar sobre lo erótico como núcleo de encuentro con la alteridad, Levinas establece de un modo más general que la apertura a la alteridad viene posibilitada por el lenguaje, "cuya esencia es la interpelación, el vocativo".22 La palabra siempre requiere que haya, como mínimo, alguien que la profiere y alguien que la recibe, implica una pluralidad originaria y permite poner en común esa pluralidad sin llegar a simplificarla; en este sentido se afirma que el lenguaje conecta lo heterogéneo: 23 "hablar es volver el mundo común". ${ }^{24}$ Lo esencial del lenguaje es "la coincidencia del revelador y de lo revelado en el rostro", 25 que funciona como elemento de apertura a la trascendencia. "El Otro tiene un rostro y es descrito mediante el rostro; he aquí la posibilidad máxima de expresión y comunicación"; 26 es la relación cara-a-cara la que me pone frente al rostro de otro y permite así el surgimiento del intercambio lingüístico; éste se enmarca ya desde el comienzo en la esfera de la ética, según el enfoque levinasiano. ${ }^{27}$

El lenguaje permite el acceso a la alteridad irreductible de lo absolutamente otro y de ahí se sigue que lo lingüístico, además de pertenecer al ámbito de la ética, se inserta en la metafísica -ambas dimensiones están estrechamente conectadas en el pensamiento de Levinas-: "la relación del Mismo y del Otro -o metafísica- funcio-

\footnotetext{
20 Palacio, M.: La mujer y lo femenino en el pensamiento de Emmanuel Levinas. Un debate de género en torno a la alteridad femenina, Córdoba, Universidad Católica de Córdoba, 2008, p. 254.

21 Ibid., p. 323.

22 Levinas, E.: op. cit., p. 92.

23 De la caracterización del lenguaje como síntesis de lo heterogéneo se ha ocupado Ricoeur en su libro Sí mismo como otro, donde desarrolla su concepción de identidad narrativa, de la que hablaremos más adelante.

24 Levinas, E.: op. cit., p. 99.

25 Ibid., p. 90.

26 Quesada Talavera, B.: en op. cit., p. 403.

27 Nótese la conexión entre este enfoque de la alteridad y las éticas dialógicas desarrolladas en el ámbito contemporáneo por Habermas o Apel, que se fundamentan en esta concepción del diálogo como el espacio ético por antonomasia.
} 
na originalmente como discurso, en el que el Mismo, resumido en su ipseidad de 'yo'-de ente particular único y autóctono- sale de sí". ${ }^{28}$ Mediante el lenguaje el yo trasciende sus propios límites y se aproxima a la alteridad radical a la que el Otro le invita a través de la palabra, en tanto que "el Yo únicamente puede salir de sí por la llamada del Otro que se produce en la relación cara-a-cara". ${ }^{29}$ Siguiendo esta lectura, es la alteridad la que interpela al Yo, la que se le presenta y le dirige la palabra, haciéndole salir de su mismidad. A partir de este argumento se entiende la crítica de Ricoeur a Levinas, al que achaca que se apoya "en la iniciativa del otro" 30 y que, en su filosofía, "el modelo de toda alteridad es el otro" 31 . Sin embargo, ese esquema "describe al otro como tan separado, aislado y solitario, que no hay encuentro posible sin incluir una dimensión complementaria que sirva como fundamento a la respuesta de responsabilidad". 32 Ricoeur busca ese complemento en el concepto de solicitud, tomado de Heidegger y que posibilita explicar con más matices el movimiento "por el que el sí se vuelve disponible para el otro distinto de sí". ${ }^{33}$ La ética cuenta con un momento de alteridad que arranca a partir de 'ser-conminado por el otro', de confrontarme al rostro del otro y relacionarme lingüísticamente con él (tal y como se ha visto en Levinas), pero en la ética hay además otros contenidos que Ricoeur inscribe en el orden de los imperativos, inspirándose en Aristóteles y Kant.

De Aristóteles toma las nociones de hábito y carácter, que le sirven para mostrar cómo "a través de esa sedimentación continua que se va formando en mí mismo, va naciendo, en virtud del hábito, una especie de segunda naturaleza humana"34 a la que Ricoeur denomina 'carácter'. El hábito fija nuestros gustos y aptitudes y con ello "reduce el campo de nuestras disponibilidades" 35 , acota y delimita nuestras potencias. El carácter, forjado a partir de los hábitos adquiridos a fuerza de repetición, marca un punto de vista ante las cosas, es el fundamento de la motivación y la acción, y su empuje nos lleva a buscar la vida buena, la 'proháiresis' aristotélica vinculada a la virtud. ${ }^{36}$ Mediante ese movimiento enraizado en el propio carácter se inicia una búsqueda del otro, una apertura a la alteridad, en la medida en que "a la estima de sí, entendida como deseo de 'vida buena', la solicitud añade esencialmente la carencia, que hace que necesitemos amigos" 37 y que pone a cada

\footnotetext{
28 Levinas, E.: op. cit., p. 63.

29 Reyes Pedraza, J.: en op. cit., p. 162.

30 Bourgeouis, P.: "Ricoeur and Levinas: Solicitude in Reciprocity and Solitude in Existence", en R.

A. Cohen y J. L. Marsh (eds.), Ricoeur as another. The ethics of subjectivity, Albany, State University of New York Press, 2002, (pp. 109-126), p. 110.

31 Ricoeur, P.: Sí mismo como otro, Madrid, Siglo XXI, 1996, p. 396. En lo sucesivo, SM.

32 Bourgeouis, P.: en op. cit., p. 110.

33 SM, p. 172.

34 Ricoeur, P.: Finitud y culpabilidad, Madrid, Taurus, 1982, p. 76. En lo sucesivo, FC.

35 FC, p. 77.

36 SM, p. 80.

37 SM, p. 200.
} 
uno en situación de dar respuesta a las expectativas del otro, cumplir las promesas que hace, estar disponible... y toda una serie de contenidos éticos que hacen emerger "determinaciones nuevas del sí". 38 Esa 'solicitud', entendida como disponibilidad para atender la llamada del otro, se concibe como un imperativo en sentido kantiano: el sí tiene "una capacidad de acogida que resulta de una estructura reflexiva", 39 y responder a las expectativas del otro es un acto de la 'buena voluntad'. Con estas consideraciones sobre la búsqueda de la vida buena a través de la sabiduría práctica y la ejercitación de la bondad como acto de la voluntad que surge a partir de la reflexión, Ricoeur pone de manifiesto que en la relación con la alteridad hay una disposición previa de lo Mismo a entrar en contacto y dejarse transformar por esos procesos de intercambio bidireccional, comunicativo y activo con lo Otro.

Asimismo, en este enfoque la alteridad se ubica en la propia estructura ontológica del Mismo, al explicarse la identidad a partir de la dialéctica o 'tensión narrativa' entre mismidad e ipseidad. El núcleo de la mismidad se conecta con la idea de unidad: soy 'yo' mismo a lo largo del tiempo, hay una cierta continuidad en la identidad -que viene dada principalmente por la identidad corporal y por los rasgos fijos del carácter anteriormente citados-. La ipseidad hace referencia a las variaciones que se producen en la identidad a lo largo del tiempo, alude al sí en tanto que sí mismo que da cuenta de sus actos insertándolos en un relato en el que cada acción cobra sentido a partir de su conexión con una totalidad constituida por el resto de acciones realizadas previamente. Desde la perspectiva de la ipseidad, la alteridad ya no es algo que provenga únicamente del encuentro con el Otro en un plano exterior, sino que forma parte de la propia estructura ontológica del individuo en cuanto ser que construye su identidad a partir de esquemas temporales, a través de distintas acciones que se superponen y articulan y cuya interconexión sólo puede explicarse narrativamente: "la alteridad no se añade desde el exterior a la ipseidad, [...] sino que pertenece al tenor del sentido y a la constitución ontológica de la ipseidad". 40 A esto se refiere Ricoeur cuando habla del 'sí mismo como otro'; esta expresión alude al extrañamiento que surge a nivel interno y que es inherente a todo proceso de construcción y variación de la identidad a lo largo del tiempo.

En síntesis, para Ricoeur la clave de la identidad individual reside en esa alternancia y combinación de mismidad e ipseidad que se entretejen e imbrican en el fluir de la vida, del que tomamos conciencia cuando le damos formato expresivo (narrativo).

Paralelamente y en conexión con estos desarrollos filosóficos contemporáneos sobre la alteridad, en décadas recientes se han suscitado distintos debates teóricos a propósito de esta noción filosófica y su utilidad en el ámbito de la ética, la filosofía

\footnotetext{
38 SM, p. 320.

39 SM, p. 377.

40 SM, p. 352.
} 
política o la psicología. La exposición de todas esas reflexiones trascendería los límites de este estudio, por lo que en las páginas que siguen nos centraremos en las consideraciones sobre la diferencia sexual desde la perspectiva de la alteridad.

\section{Alteridad sexual y heterodesignación}

La alteridad se manifiesta en el lenguaje, en la medida en que éste posibilita una apertura al otro sin cancelar por ello su diferencia radical, su separación originaria con respecto a mí. Es precisamente esa dimensión lingüística y simbólica de la alteridad la que proporciona una de las claves fundamentales para entender la crítica del feminismo contemporáneo al patriarcado. Este enfoque señala que en el discurso filosófico ha predominado "una centralidad de la diferencia masculina, asumida como criterio de valor para juzgar la diferencia femenina". ${ }^{41} \mathrm{La}$ alteridad sexual, establecida en torno a la dicotomía masculino-femenino, ha funcionado como criterio de jerarquización -se ha producido el paso del 'es' de la diferenciación sexual biológica al 'debe' propio del ámbito de los valores, incurriendo así en la falacia naturalista-, de tal modo que en la relación entre ambos sexos "el hombre representa al mismo tiempo el positivo y el neutro. [...] La mujer aparece como el negativo". 42 Sucede así que al orden biológico, que implica la dualidad sexual, se superpone un orden simbólico que aplica diferentes valores a cada uno de los polos de esa dualidad.

Según la crítica iniciada por Beauvoir, en esa construcción simbólica lo masculino se ha erigido en pauta de lo universal por contraposición a lo femenino, recluido en la esfera de lo particular: "la mujer se determina y se diferencia con respecto al hombre, y no a la inversa; ella es lo inesencial frente a lo esencial. Él es el Sujeto, es el Absoluto: ella es la Alteridad". ${ }^{43}$ La mujer es definida como lo Otro siempre con respecto a lo Uno, y el patrón de lo Uno -que es también el patrón de lo universal- está constituido desde el punto de vista masculino.

Esa preeminencia que la filosofía ha otorgado a lo unitario es identificada como la principal causa de la desvalorización de la diferencia: lo Uno -el Hen de Parménides- tiene prioridad ontológica sobre lo múltiple, y de ese modo la multiplicidad/alteridad queda relegada a un segundo plano, ya que es categorizada como inferioridad; sólo en épocas muy recientes el discurso de la multiplicidad ha cobrado protagonismo en la reflexión filosófica ${ }^{44}$, pero en todo caso con un papel secundario con respecto al pensamiento de lo Uno. Históricamente, "la razón occidental se

\footnotetext{
41 Tomassi, W.: Filósofos y mujeres, Madrid, Narcea, 2002, p. 14.

42 Beauvoir, S. de: El segundo sexo. Vol. I: Los hechos y los mitos, Madrid, Cátedra, 2002, p. 49.

43 Ibid., p. 50.

44 Como es sabido, este enfoque es predominante en la corriente hermenéutica.
} 
sitúa a sí misma como el discurso del sujeto idéntico a sí mismo, y de ese modo bloquea y deslegitima de hecho la presencia de la otredad y de la diferencia que no encaja en sus categorías" 45 ; y esta construcción teórica hegemónica ha servido como argumento para legitimar la exclusión y discriminación de las mujeres y de otros colectivos culturales, étnicos o religiosos que han sido etiquetados como 'diferencia'.

Otros estudios han destacado además que el carácter de 'alteridad' que se aplica a las mujeres surge como resultado de un proceso de heterodesignación. Mediante los actos lingüísticos se aplican y hacen efectivas las marcas de género, los cuerpos son designados como masculinos o femeninos a través del discurso y, dado que esa construcción verbal de las identidades sexuales se lleva a cabo dentro del contexto patriarcal, es el punto de vista masculino el que define a la mujer. Quienes ocupan las posiciones de poder tienen la potestad de fijar las normas del discurso y definir el lenguaje, y el feminismo denuncia que las mujeres han sido excluidas de ese espacio de poder y a consecuencia de ello no han participado en la configuración de las categorías que las definen. Han sido heterodesignadas como 'diferencia' con respecto a lo 'normal', y la pauta de lo 'normal' es masculina: "las mujeres [...] no dicen 'nosotras'; los hombres dicen 'las mujeres' y ellas retoman estas palabras para autodesignarse, pero no se afirman realmente como Sujetos" 46 sino que quedan relegadas al papel de objetos frente al sujeto masculino que las nombra. En esta línea, análisis más recientes inspirados en Foucault han insistido en que el lenguaje se constituye como poder, en tanto que los nombres delimitan, etiquetan y producen las condiciones de viabilidad de los sujetos ${ }^{47}$; además, al establecer el dominio de la inteligibilidad cultural, el discurso funciona como sistema de exclusiones: incluye a unos y deja fuera a otros y, en última instancia, demarca y restringe el espacio de la alteridad.

El proceso de 'etiquetado' que lleva a cabo el lenguaje crea categorías como masculino-femenino, homosexual-heterosexual, belleza-fealdad, y toda un larga serie de términos duales que marginan a quienes no encajan de modo claro en alguno de esos parámetros binarios. De ese modo, acontece que por mediación del lenguaje la alteridad se transforma en jerarquía: "es el lenguaje el que codifica y dictamina toda servidumbre, el que marca lo que se puede o no se puede, lo que se debe o no se debe"; 48 en resumen, el lenguaje construye 'la verdad', nombra el mundo y determina lingüísticamente sus límites, dejando al margen a las mujeres. Se denuncia que ese silenciamiento forma parte del sutil sistema de opresión elaborado por

\footnotetext{
45 Benhabib, S.: "Feminism and Postmodernism: an uneasy Alliance", en S. Benhabib et al. (eds.): Feminist contentions: a philosophical exchange, New York y Londres, Routledge, 1995, (pp. 17-34), p. 19.

46 Beauvoir, S. de: op. cit., p. 53.

47 Butler, J.: Bodies that matter: On the discursive limits of 'sex', New York, Routledge, 1993, cap. VII.

48 Cereceda, M.: El origen de la mujer sujeto, Madrid, Tecnos, 1997, p. 17.
} 
el patriarcado: el uso del lenguaje es una marca de poder, conlleva un privilegio, y vetar a las mujeres el acceso al discurso implica cancelar su derecho a la comunicación con el otro y a ser artífices de su propia identidad, que siempre se construye en diálogo con el mundo, abriéndose a la alteridad.

Lo masculino y lo femenino son dos polos irreductibles de una totalidad en la que ambas partes se necesitan, hombres y mujeres deberían verse como complementarios y, a partir de esa complementariedad, establecer relaciones basadas en la reciprocidad. Sin embargo, es obvio que "los dos sexos nunca han compartido el mundo en pie de igualdad". ${ }^{49}$ Así las cosas, se constata que la construcción simbólica de la mujer como alteridad irreductible con respecto a lo masculino ha tenido consecuencias muy negativas, puesto que la mujer "se descubre y se elige en un mundo en el que los hombres le imponen que se asuma como la Alteridad; se pretende petrificarla como objeto, condenarla a la inmanencia". 50

Partiendo de estas consideraciones se entiende la crítica que Beauvoir plantea a Levinas a propósito de su afirmación de que 'la alteridad se hace realidad en lo femenino'51; la filósofa detecta aquí un sesgo androcéntrico: la mujer es caracterizada como lo inasequible o insondable, como misterio, pero esa definición se apoya en un sujeto masculino que es situado ante un rostro femenino, "sin señalar la reciprocidad de sujeto y objeto". 52 En esa relación la mujer queda reducida a un mero aparecerse, se le confiere el estatus de objeto y queda incapacitada para erigirse en sujeto -porque, como denuncia el feminismo, la noción filosófica de subjetividad se ha constituido dentro del marco de referencia del pensamiento patriarcal en el que históricamente ha surgido-. Levinas "enuncia que la mujer es la alteridad por excelencia desde una posición sexuada de sujeto enunciador masculino", 53 se hace así patente que su definición de la alteridad está basada en la dicotomía jerarquizada masculino/femenino en la que el hombre se posiciona como subjetividad, como lo Mismo, frente a la mujer que es categorizada como lo Otro, como alteridad irreductible. En resumen, el desencuentro entre Levinas y Beauvoir se debe a que

para Levinas lo femenino, en cuanto otro absoluto, es una esencia ontológica que designa a todas las mujeres; en cambio para Beauvoir lo femenino es una categoría histórico-cultural construida como 'lo Otro' respecto al sujeto emisor-pensante. 54

Diversos análisis han mostrado que en el ámbito del pensamiento occidental la mujer ha sido construida como paradigma de todas las alteridades: "El hombre

\footnotetext{
49 Beauvoir, S. de: op. cit., p. 55.

50 Ibid., p. 63.

51 Beauvoir recoge esta crítica a Levinas en op. cit., pp. 50-51, nota 3.

52 Ibid., p. 51, nota 3.

53 Palacio, M.: op. cit., p. 281.

54 Ibid., p. 441.
} 
busca en la mujer el Otro como Naturaleza y como su semejante" 55 ; y las mujeres y sus cuerpos "representan la 'naturaleza' que debe ser controlada y trascendida si el orden social ha de ser creado y mantenido". $56 \mathrm{El}$ cuerpo femenino encarna la otredad, la diferencia en sentido más radical: es identificada con las fuerzas irracionales de la naturaleza, que se contraponen a la racionalidad del discurso filosófico y científico ${ }^{57}$; y es asimismo diferencia en un sentido antropológico: es diferente de lo masculino, es la alteridad/la Otra con respecto a la norma de lo universal. Esa heterodesignación es alienante para las mujeres, que según este esquema representativo son "todo lo que el hombre busca y todo lo que no alcanza"58; la asimetría de esta relación entre los dos sexos es evidente: él es sujeto, ella es objeto; él toma la iniciativa de la búsqueda, ella es lo hallado, el premio, la recompensa ${ }^{59}$.

Al ser heterodesignada como alteridad, la mujer es privada de los mecanismos que le permitirían construir su propia identidad desde unos presupuestos más flexibles y menos condicionados por su relación con lo masculino -tanto en un sentido literal como en un sentido simbólico-. La mujer

como alteridad, lo es también para sí misma [...] Al serlo todo, nunca es precisamente aquello que debería ser; es la perpetua decepción, la decepción misma de la existencia que nunca consigue alcanzarse y reconciliarse con la totalidad de los existentes ${ }^{60}$.

El hecho de ser definida como alteridad para otro es un foco de frustración, provoca que la mujer quede recluida y atrapada en ese espacio simbólico y se le deniegue la posibilidad de que emprenda por sí misma la búsqueda de nuevos criterios de identidad y alteridad y que los redefina a partir de sus propias coordenadas. "Lo femenino en cuanto lo Otro(a) del sujeto permanece como pieza funcional a la trascendencia del sujeto masculino sin lograr su propia trascendencia". 61 Además, esa búsqueda se ve entorpecida también por la falta de acceso al discurso a la que nos hemos referido anteriormente.

\footnotetext{
55 Beauvoir, S. de: op. cit., p. 230.

56 Pateman, C.: El contrato sexual, Barcelona, Anthropos, 1995, p. 135.

57 El ecofeminismo ha reflexionado sobre esta identificación entre mujer y naturaleza y ha puesto de relieve las conexiones existentes entre antropocentrismo y androcentrismo. Los trabajos de María Xosé Agra, Alicia Puleo, Maria Mies, Vandana Shiva o Karen Warren abordan de lleno estas cuestiones.

58 Beauvoir, S. de: op. cit., p. 288.

59 Para un análisis semiótico sobre este rol de la mujer como 'recompensa' para el 'héroe' en los relatos de ficción y en el cine, vid. Lauretis, T. de: Alicia ya no, Madrid, Cátedra, 1992.

60 Beauvoir, S. de: op. cit., p. 289. Sobre esta cuestión, recordemos las afirmaciones de Hegel: 'las mujeres pertenecen a la familia, están fuera de la ciudadanía y de los intereses universales'; Kierkegaard: 'la mujer es un ser al que la palabra existencia le viene grande', o Nietzsche: 'las mujeres no son libres'. Cfs. Valcárcel, A.: La política de las mujeres, Madrid, Cátedra, 1994, passim. 61 Palacio, M.: op. cit., p. 434.
} 
Es en los mitos y en la literatura donde se identifica con mayor claridad -y donde se institucionaliza- esa construcción hegemónica de los estereotipos de la feminidad; en el ámbito del imaginario del colectivo se percibe que la mujer "aparece como la Alteridad privilegiada a través de la que se realiza el sujeto: una de las medidas del hombre, su equilibrio, su salvación, su aventura, su felicidad". ${ }^{2} \mathrm{La}$ identidad femenina, en todo lo que tiene de construcción sociocultural, recibe la influencia de esas pautas y roles que las distintas tradiciones le han asignado, y que en general sitúan a las mujeres en una posición jerarquizada inferior a la de los hombres. 63 Para corregir esta situación, una de las estrategias consiste en desarrollar una lectura crítica de los mitos, ya que "el mito de la Mujer sustituye las relaciones auténticas con un existente autónomo por la contemplación inmóvil de un espejismo" 64 que, en la práctica, recluye a las mujeres en la parálisis del 'eterno femenino'. Otras estrategias, planteadas principalmente en el contexto del feminismo de la diferencia, pasan por una reformulación alternativa de lo femenino como alteridad 'para sí' y la creación de nuevos imaginarios más extensos que incluyan los puntos de vista y experiencias de las mujeres. ${ }^{65}$

La solución emancipadora que Beauvoir plantea, y que es común -aunque con matices- a todo el feminismo de la igualdad, implica que la mujer tenga "acceso al mundo masculino como el varón al mundo femenino". ${ }^{6}$ El modelo de trascendencia que propone es el masculino: "para 'rehacer la mujer' la sociedad tendría que convertirla realmente en una igual del hombre". 67 Esa relación igualitaria no cancela la alteridad sexual, sino que la redefine y la enmarca en un plano más justo: "al reconocerse mutuamente como sujetos, cada uno seguirá siendo para el otro una alteridad"; 68 se percibe en esta propuesta una dimensión ética que tiñe todo el pensamiento feminista desarrollado a partir de Beauvoir, y que conecta con las reflexiones sobre la alteridad de Levinas y Ricoeur anteriormente expuestas.

\section{Maternidad, alteridad y ética del cuidado}

El cuerpo femenino tiene la posibilidad de gestar, de crear vida. Este hecho biológico, que diferencia a hombres y mujeres en términos generales, ha dado lugar a una amplia elaboración simbólica a propósito de la maternidad planteada desde

\footnotetext{
62 Beauvoir, S. de: op. cit., p. 345.

63 Sobre los estereotipos de género reflejados en la mitología, la literatura y el arte, cfs. Bornay, E.: Las hijas de Lilith, Madrid, Cátedra, 1990.

64 Beauvoir, S. de: op. cit., p. 359.

65 De estas propuestas nos ocuparemos en el siguiente epígrafe.

66 Beauvoir, S. de: El segundo sexo. Vol. II: La experiencia vivida, Madrid, Cátedra, 2002, p. 498.

67 Beauvoir, S. de: op. cit. vol. II, p. 541.

68 Beauvoir, S. de: op. cit. vol. II, p. 544.
} 
múltiples puntos de vista. Nos centramos aquí en el feminismo de la diferencia, cuya reflexión ofrece elementos muy valiosos para ampliar el pensamiento de la alteridad.

Desde esta perspectiva se descarta la heterodesignación y se acomete el proyecto de desterrar la definición de 'mujer' construida desde el punto de vista masculino y sustituirla por otros significados articulados desde el lado femenino, esto es, formulados desde el otro lado de la alteridad. En esa búsqueda de nuevos referentes la experiencia de la gestación y la maternidad ha resultado particularmente inspiradora, hasta el punto de reivindicarse "el derecho a la maternidad como componente de la identidad femenina"69, aunque sin perder de vista que "la maternidad, en el sentido de una relación intensa, recíproca, con un hijo [...] es una parte del proceso femenino, no se trata de una identidad permanente". ${ }^{70} \mathrm{Si}$ se logra eludir el riesgo entrañado por la defensa de posturas que refuercen una definición esencialista de 'lo femenino' apoyada en los roles tradicionales de esposa y madre atribuidos históricamente a las mujeres, resulta interesante ahondar en los contenidos culturales y experienciales de la maternidad.

Frente al discurso filosófico que ha elaborado metáforas sobre la capacidad femenina de gravidez y alumbramiento y que se ha apropiado simbólicamente de esa vivencia de las mujeres -recordemos, por ejemplo, el método mayéutico de Sócrates, que consistía en 'ayudar a dar a luz' las ideas que su interlocutor tenía dentro de sí-, se promueve una indagación en los puntos de vista de las mujeres con respecto a la experiencia única de gestar, dar a luz y amamantar a los hijos e hijas.

En la tradición occidental ha predominado la visión de la maternidad como un poder femenino negativo y peligroso que debía someterse al control masculino. Para superar esta interpretación se aborda el cuerpo materno desde una perspectiva emancipadora; éste "proporciona tanto el lugar de destitución como de recuperación de la subjetividad femenina feminista", 71 y puede inspirar nuevos modelos de trascendencia que han de ser renegociados en el orden simbólico. En estas aproximaciones alternativas el cuerpo materno es tomado como referente para una relación de solidaridad, de aprendizaje mutuo y de reconocimiento de autoridad entre mujeres. A grandes rasgos, se postula que los canales de empatía que se establecen entre las mujeres y sus hijos e hijas pueden servir de inspiración para articular nuevos paradigmas relacionales que potencien el valor de la diferencia y el encuentro con la alteridad. En ese proyecto de pensar la diferencia, inscrita ya desde el inicio en cada individuo en tanto que éste se inserta en la corriente de la vida -todo ser humano ha sido engendrado por otra pareja anterior, y así sucesivamente-, la maternidad

\footnotetext{
69 Irigaray, L.: Yo, tú, nosotras, Madrid, Cátedra, 1992, p. 86.

70 Rich, A.: Nacemos de mujer. La maternidad como experiencia e institución, Madrid, Cátedra, 1996, p. 76.

71 Braidotti, R.: Metamorfosis. Hacia una teoría materialista del devenir, Madrid, Akal, 2005, p. 70.
} 
es interpretada como "un espacio común, inaugura la relación con lo otro que está presente en el ser humano desde su gestación; en este sentido la maternidad trasciende lo biológico y abre el camino de la alteridad". 72

De la relación con la madre emerge un posible punto de partida para esa búsqueda de un discurso propio que exprese adecuadamente la corporalidad y particularidades de las mujeres y que, en definitiva, dé cuenta de la alteridad femenina desde el otro lado del espejo. Luce Irigaray sostiene que el cuerpo femenino está abierto a la heterogeneidad precisamente porque en su propia estructura biológica lleva inscrita la capacidad de que en su organismo crezca y prolifere lo diferente, lo otro. En consonancia con esta tesis, Hélène Rouch describe la gestación como

proceso de construcción de la dualidad de dos cuerpos donde la identidad, como expresión de la especificidad y por tanto marca de la diferencia, en lugar de provocar la exclusión del otro podría, al contrario, ser la señal que inicia su aceptación. ${ }^{73}$

La experiencia de la gestación se redefine como un espacio de negociación entre lo uno y lo múltiple y se desvela como un contexto privilegiado donde se trasciende la barrera entre el 'yo' y el 'otro' y donde la identidad se abre a la alteridad de modo radical. Rosi Braidotti abunda en estas propuestas al señalar la contribución del feminismo a la reflexión sobre "los espacios intermedios entre lo mental y lo físico, o entre lo teórico y lo experiencial". ${ }^{74}$ Uno de esos espacios intermedios es el cuerpo gestante, que funciona como núcleo de experiencias en el nivel somático y, al mismo tiempo, ofrece elementos para una articulación simbólica que el feminismo más reciente ha sabido aprovechar.

Al igual que Luce Irigaray, Luisa Muraro critica que el orden social patriarcal niega el vínculo con la madre ${ }^{75}$. El discurso filosófico se despliega poniendo entre paréntesis todo aquello que normalmente tenemos presente, se desvincula del territorio y la materia, y al hacerlo produce una ruptura con los lazos afectivos, incluido el de la madre. La recuperación del orden simbólico de la madre ha de realizarse en el plano ontológico, porque "el sentido del ser sólo se puede aprehender plenamente a partir de nuestra relación con la matriz de la vida, y esa relación es la que se establece con la madre en la primera infancia". ${ }^{76}$ La metafísica occidental, en su proceso de 'olvido del ser', ha desconectado a ese ser de la esfera de la vida, y el

\footnotetext{
72 Fernández Guerrero, O.: "Encuentros y desencuentros entre el feminismo y la maternidad", en G. Franco Rubio (ed.), Debates sobre la maternidad desde una perspectiva histórica (Siglos XVI-XX), Barcelona, Icaria, 2010, (pp. 425-438), p. 437.

73 Rouch, H.: "La gestation, paradoxe immunologique de la dualité", en Rouch et al. (eds.): Le corps, entre sexe et genre, Paris, L'Harmattan, 2005 (pp. 105-126), p. 106.

74 Braidotti, R.: Metamorfosis..., ed. cit., p. 92.

75 Muraro, L.: El orden simbólico de la madre, Madrid, Horas y horas, 1994, pp. 59 a 61.

76 Ibid., p. 28.
} 
único modo de recuperar la conexión es a través de un trabajo simbólico que pasa por reanudar la relación con la madre -con lo maternal-.

Según Muraro, el sentido del mundo y de la vida comienza a construirse en los primeros meses de vida en el seno del vínculo con la madre, es una especie de 'saber precategorial' que está dado de forma inmediata en la relación materno-filial:

La fijación a la madre obra en nosotros como el grano de arena en la madreperla, activando la estructura circular propia de la mediación y dando lugar así a la dimensión simbólica. 77

La relación con lo maternal se constituye como alteridad primera y originaria que da fundamento al sentido y permite la adquisición del lenguaje -que, como afirma Levinas, es la puerta de acceso a una relación no reduccionista con la alteridad-. Se pone de relieve que el lenguaje es apertura, pero se insiste además en que el primer contacto con lo lingüístico, que da paso a lo simbólico, surge originariamente de la conexión inmediata con la vida ${ }^{78}$, explicitada en la relación primordial que cada individuo mantiene con su propia madre durante la gestación, el nacimiento y la lactancia. En el esfuerzo por superar un modelo de saber basado en el sujeto solipsista, se insiste en que toda posibilidad de aprendizaje brota de esa inmersión primera en la lengua materna, porque "las madres enseñan a hablar". 79

Para elaborar ese nuevo lenguaje que habla 'en femenino', uno de los referentes básicos es el simbolismo de la fluidez: frente a lo fálico, caracterizado como lo rígido, duro y unitario, se defiende el paradigma de lo líquido, por cuanto "nosotras conocemos suficientemente los contornos de nuestros cuerpos para amar la fluidez". $80 \mathrm{Si}$ el cuerpo femenino es capaz de albergar otro cuerpo dentro de sí, ello posibilita que las mujeres puedan desarrollar otros modelos de relación complementarios en los que prima el 'intercambio fluido', tomado en sentido literal cuando hace referencia a experiencias como la gestación o la lactancia, pero que también puede ser reinterpretado simbólicamente en términos de apertura a lo diferente, de hacerse 'permeable' al otro y superar la separación radical entre lo Uno y lo Otro que ha predominado en la historia de la filosofía occidental. La mayor crítica que se puede realizar a esta propuesta es el excesivo optimismo que muestra Irigaray al suponer que es posible prescindir completamente del punto de vista masculino a la hora de redefinir 'lo femenino'.

El feminismo de la diferencia se ha inspirado, al menos en parte, en el modelo de alteridad planteado por Levinas, y ha llegado a afirmar que "el sujeto levinasiano es en el fondo un 'sujeto feminizado', enternecido, maternal, capaz de donarse y sus-

\footnotetext{
77 Ibid., p. 57.

78 Es evidente la proximidad de este planteamiento a las tesis de Husserl sobre el 'mundo de la vida'.

79 Muraro, L.: op. cit., p. 19.

80 Irigaray, L.: Ce sexe qui n'en est pas un, Paris, Éditions de Minuit, 1977, p. 214.
} 
tituirse por el otro". 81 Pero esta lectura resulta problemática, en buena medida porque la noción de alteridad que Levinas aplica a lo femenino acaba recluyendo a las mujeres reales en esa esfera simbólica relacionada con 'el misterio' y 'lo otro' de lo masculino, como ya indicó Beauvoir. Al inscribir la alteridad femenina en las esferas de lo erótico, por un lado, y de lo doméstico, por otro, ${ }^{82}$ Levinas queda atrapado en un discurso profundamente conservador con respecto a las mujeres. Con todo, y a pesar del sesgo androcéntrico que se detecta en su filosofía, su intento de superar la ontología de lo Uno puede servir como cauce de inspiración para el pensamiento de la diferencia sexual, siempre y cuando se evite esencializar esa diferencia. 83

No hay un único modo de ser de lo femenino sino que existen las mujeres en plural, y cualquier planteamiento de la diferencia que se realice con rigor ha de tener en cuenta esa multiplicidad de planos que se superponen e interactúan en todo proceso de configuración de las identidades: el género, la clase social, la posición económica, el entorno familiar, la nacionalidad, el grupo cultural de referencia...

Sin perder de vista esta conceptualización de la diferencia como núcleo amplísimo e irreductible de heterogeneidades - y de alteridades-, la recuperación simbólica de la figura de la madre puede ayudar a introducir otras actitudes complementarias desde las que abordar la relación con el otro: la afectividad desinteresada y altruista, el amor productivo, la tolerancia o el pacifismo ${ }^{84}$. El núcleo de la ética se ensancha con estas aportaciones de la teoría feminista y se nutre de nuevos argumentos desde los que problematizar la relación con la alteridad.

Uno de los ejemplos más interesantes en esta línea es el de Carol Gilligan ${ }^{85}$, que ha mostrado que el desarrollo moral de las mujeres difiere, en términos medios, del

81 Palacio, M.: op. cit., p. 429.

82 Recordemos que, según este autor, el erotismo es uno de los espacios de relación privilegiada con la alteridad, en la medida en que 'la amada' se presenta como 'lo que está más allá del objeto y del rostro'. El otro espacio peculiar de encuentro con la alteridad es la casa, a la que Levinas atribuye una 'dimensión de feminidad' basada en el recibimiento hospitalario que la morada proporciona. Cfs. Levinas, E.: Totalidad e infinito. Ensayo sobre la exterioridad, ed. cit.

83 Esta interpretación se complementa con las aportaciones planteadas por Stella Villarmea, que considera que la identificación que realiza Levinas de la mujer con lo Otro no sirve bien a los propósitos feministas, al menos en principio. Esta autora considera, por una parte, que las afirmaciones de Levinas acerca de la mujer no contribuyen en modo alguno a su emancipación, y sostiene asimismo que la doctrina sobre la alteridad desarrollada por este filósofo es excesivamente abstracta como para ser utilizada por el feminismo. Por tanto, concluye Villarmea, todo planteamiento feminista basado en la doctrina de Levinas habrá de llevar a cabo una crítica de los elementos androcéntricos presentes en su teoría, y dotar de nuevos contenidos a su concepción tan general y abstracta de la alteridad. Cfs. Villarmea, S.: "The provocation of E. Levinas for feminism", The European Journal of Women's Studies, 6.3, 1999, pp. 291-304.

84 Sobre la actitud maternal como fundamento de una teoría pacifista y antimilitarista, vid. Ruddick, S.: Maternal thinking. Towards a Politics of Peace, London, Wordsworth, 1990.

85 Gilligan, C.: "Con otra voz: las concepciones femeninas del yo y de la moralidad", en M. T. López de la Vieja et al. (eds.), Bioética y feminismo. Estudios multidisciplinares de género, Salamanca, Universidad de Salamanca, 2006, pp. 15-56. 
de los hombres: en las pautas morales femeninas se detecta mayor atención a lo concreto y a los contextos de la acción, mientras que en los hombres hay más predominio de los principios de autonomía y justicia. En discrepancia con las valoraciones de Piaget o Kohlberg, que establecen que en la fase más avanzada del desarrollo moral individual se alcanza una visión basada en la autonomía y la justicia, Gilligan considera que el modelo de moralidad femenina es 'otra voz' que complementa la ética al introducir en ella el principio de no hacer daño (que atiende a las consecuencias de las decisiones individuales) y el principio del cuidado (que implica una reflexión sobre las relaciones interpersonales y las responsabilidades hacia los demás). Estas reflexiones sobre el principio del cuidado surgen en un primer momento en estrecha conexión con la experiencia de la maternidad vivida por muchas mujeres. Ser madre implica cuidar a otro en una relación no recíproca; aceptar la responsabilidad de sustentar la vida de otro que depende completamente de la madre para poder existir -el ejemplo más claro de esa dependencia lo hallamos en la gestación: la viabilidad del feto está en manos de la madre que lo alberga en su cuerpo-; tolerar el crecimiento de 'otro que no es yo' dentro de mí, etcétera.

Cada vez que un individuo nace y surge en el mundo, la actitud de cuidado marca la pauta de conducta que permitirá que ese individuo sobreviva y salga adelante: cuidar implica alimentar, limpiar, estimular y educar a ese ser indefenso para que llegue a desarrollarse en relación con los otros. El cuidado se hace asimismo extensivo a otras personas que, de modo transitorio o definitivo, están en situación de dependencia debido a enfermedades, discapacidad, edad avanzada, etcétera. Según reivindica la ética feminista, el principio de cuidado es valioso porque permite mejorar las condiciones de vida y de dignidad de quienes reciben ese cuidado, pero su aplicación no puede exigirse únicamente a las mujeres -que son las que lo han ejercido y siguen ejerciendo mayoritariamente-, sino que ha de ser una actitud fomentada entre toda la ciudadanía y reforzada desde las instituciones.

El encuentro con la alteridad se redefine en este planteamiento desde un horizonte ético en el que el Otro nos interpela, su desvalimiento nos incita a prestarle ayuda y asumir un compromiso de cuidado con respecto a él. Pero ese compromiso no ha de ser adoptado únicamente a título individual -como expone Levinas-, sino que el feminismo promueve el cuidado como algo que debe institucionalizarse, pues es valioso en sí mismo y con pretensiones de universalidad.

\section{Notas para una concepción dinámica de la alteridad sexual}

A partir de los análisis fenomenológicos y hermenéuticos, la identidad se problematiza y se concibe como un proceso abierto en el que confluyen distintos elementos. En este enfoque la identidad individual se perfila como un núcleo más o 
menos cohesionado que se va modificando a lo largo de la existencia a partir de la inserción en el 'mundo de la vida' y de las sucesivas transformaciones que se producen en cada individuo por medio de la relación con la alteridad. Husserl, Heidegger, Dilthey, Sartre, Ricoeur o Gadamer han explicado cómo las identidades individuales se configuran a partir del espacio (cada yo está 'en situación', es un ente en medio de las cosas y se relaciona con su contexto vital) y del tiempo (el yo tiene continuidad temporal, se articula como síntesis y conexión de sucesivos instantes). La hipótesis de partida es que, según afirma Ricoeur, "el 'quién' se dice de muchas maneras", 86 y desde ese prisma el enfoque dialéctico parece el más oportuno para abordar en toda su complejidad el estudio de la identidad, constituida a partir de la tensión entre lo mismo y lo otro: el yo se mantiene a lo largo del tiempo pero no es una entidad inmutable, sino que experimenta constantes alteraciones.

Se produce así la paradoja de que el 'yo', que es dinámico, se autopercibe y es percibido desde fuera como 'el mismo' a lo largo de toda esa concatenación de cambios que la existencia implica, de tal modo que "la identidad del yo o 'mismidad' que mantiene en un haz lo simultáneo y lo sucesivo de los diversos procesos de la vida nos revela $[\ldots]$ contradicciones". ${ }^{87}$ Ricoeur sostiene que esas contradicciones surgen porque lo que entendemos por 'identidad' tiene, al menos, tres significados distintos: identidad numérica (referida a la unicidad del yo); identidad cualitativa (semejanza extrema del yo consigo mismo a lo largo de las distintas variaciones temporales); y continuidad ininterrumpida (consideramos que, en el último estadio de desarrollo del individuo, éste sigue siendo el mismo que al inicio del proceso). Según este esquema, la identidad surge a partir de la confluencia de distintos planos y su estructura se apoya en la tensión entre lo uno y lo múltiple que se establece, a nivel interno y externo, en el contexto concreto de cada individualidad.

Este modelo explicativo puede extrapolarse a los planteamientos sobre la identidad sexual desarrollados en la teoría feminista más reciente, que intenta superar el dualismo masculino/femenino y dar una visión más matizada de los procesos por los que se llega a ser 'hombre' o 'mujer'. La propuesta se sustenta sobre la noción de 'poiesis' o 'performatividad', que permite definir la identidad sexual como una construcción que se ejecuta por medio de la suma de distintos actos de un agente; esos actos son 'para sí', en tanto que el individuo se sirve de ellos para 'crear' su propia identidad sexuada, pero también son actos 'para otro', ya que conllevan la puesta en escena de roles y pautas culturalmente asignados a lo masculino o lo femenino.

\footnotetext{
86 SM, Prólogo, p. xxxii.

87 Dilthey, W.: "Ideas acerca de una psicología descriptiva y analítica", en E. Ímaz (coord.), Obras de Wilhem Dilthey VI. Psicología y Teoría del Conocimiento, México, Fondo de Cultura Económica, 1978, p. 221.
} 
La identidad sexual atribuida los cuerpos en el momento de nacer -y que, en este sentido, funciona como una heterodesignación- no es algo natural ni dado a priori sino que se postula como un desiderátum, ha de ser construida, marca el punto de partida de un proceso en el que cada individuo 'actualiza' su género, asimila las pautas de masculinidad o feminidad correspondientes a la categoría a la que ha sido adscrito y las aplica al contexto concreto de su existencia (recordemos al respecto la frase de Simone de Beauvoir: 'no se nace mujer, se llega a serlo'). A partir de estos presupuestos la identidad sexual es reinterpretada como un devenir, un despliegue inacabado en el que el 'yo' -sexuado- se mantiene a lo largo del tiempo, se modifica a través de sus actos y mediante éstos reedita $-\mathrm{o}$ incluso renegocia- esa marca de género que, desde el inicio de su existencia, lo ha ubicado a uno de los dos lados de la dicotomía masculino/femenino.

A cada individuo le corresponde desde su nacimiento una identidad de 'hombre' o 'mujer', pero esa identidad ha de ser desarrollada, es tarea del individuo materializarla a través de sus actos e inscribirla en su cuerpo, puesto que "los cuerpos materializan el 'sexo' en la medida en que repiten las normas". ${ }^{88}$ Las identidades de género están codificadas social y culturalmente, "existen prácticas reguladoras que generan identidades coherentes" 89 y una de esas prácticas -quizás la más poderosaes el establecimiento del sistema oposicional masculino/femenino. El problema es que ese marco normativo ha llegado a generalizarse e institucionalizarse hasta tal punto que el género, que no deja de ser una construcción culturalmente mediada, "acaba consolidándose como algo aparentemente natural, [...] una sustancia". $90 \mathrm{Se}$ critica la esencialización de las identidades femeninas y masculinas y se aboga por una visión más dinámica que permita explicar cómo se codifican los términos en que ha de manifestarse la alteridad sexual y que incremente las opciones de transgresión y transformación de esos códigos. Si la masculinidad y feminidad no son algo dado a priori, sino que están en permanente construcción, es posible modificar ese proceso y promover identidades de género más flexibles y emancipadoras, que den cabida a la diferencia concebida como un fenómeno múltiple que trasciende el dualismo inmovilista masculino/femenino.

Según Butler, la dialéctica entre lo Mismo y lo Otro desarrollada por Levinas y otros filósofos resulta inadecuada porque "esconde la falacia de una diferencia entre sexos como categorías mutuamente excluyentes". ${ }^{91}$ La tensión debe desplazarse al terreno de la propia individualidad y a la confrontación de cada cual consigo mismo que todo proceso de construcción de la identidad sexual entraña. El género es una

\footnotetext{
88 Butler, J.: Bodies that matter..., ed. cit., p. 2.

89 Butler, J.: Gender trouble. Feminism and the subversion of identity, New York, Routledge, 1990, p. 17.

90 Ibid., p. 33.

91 Ibid., p. 113.
} 
puesta en escena, "es repetido de modo ritual"92, se actualiza a partir de una serie de actos corporales, movimientos y estilos que el individuo ejecuta y que ha de repetir incesantemente para dar continuidad a esa identidad de género. Sin embargo, y siguiendo en este punto a Derrida, se plantea que esa necesidad constante de actualización y repetición hace emerger la posibilidad de un cambio; es posible introducir variaciones, modificar las pautas de género y llevar a cabo lo que Butler denomina 'actos subversivos del cuerpo', que contradigan las estrictas pautas con que se ha tipificado tradicionalmente la masculinidad y la feminidad.

La teoría feminista contemporánea asume que "el mundo está lleno de infinitas posibilidades de desafiar el sistema de dos sexos establecido por la política de género" 93 y se propone explorar esas posibilidades de un modo creativo tomando el cuerpo como punto de partida, desde la convicción de que ha sido la rígida adscripción de patrones de conducta a los cuerpos etiquetados como 'femeninos' la que ha lastrado y sigue lastrando la emancipación de las mujeres y, en general, de todo individuo marcado como 'diferente' o 'inviable' con respecto a ese esquema normativo.

La alteridad es abordada como un fenómeno multiforme y complejo que se localiza en el núcleo de las identidades individuales, y que adquiere además dimensiones éticas y políticas: "convivir con la esquizofrenia de hacer diferentes cosas, de tener múltiples capas de identidad (feminista, blanca, universitaria...) es una forma de resistencia activa". ${ }^{4}$ La diferencia forma parte constitutiva de toda identidad, y la valoración de esa diferencia en toda su amplitud permite eludir todo intento de esencializar la identidad masculina o femenina; las identidades no son algo permanente sino que se van construyendo y modificando a lo largo de la existencia, tal y como han mostrado los estudios de Dilthey, Ricoeur o Sartre. Inspirándose en estas aproximaciones, el reto consiste en superar las explicaciones binarias y aceptar "la identidad como sitio de diferencias". 95 De este modo la alteridad entra de lleno en la constitución de la identidad, al menos en dos sentidos:

La identidad es un juego de aspectos múltiples, fracturados, del sí mismo; es 'relacional', por cuanto requiere un vínculo con el 'otro'; es retrospectiva, por cuanto se fija en virtud de la memoria y los recuerdos, en un proceso genealógico. 96

La identidad es reformulada como síntesis compleja -y no exenta de conflictosde alteridades de diversa procedencia:

\footnotetext{
92 Butler, J.: Excitable speech. A politics of the performative, New York, Routledge, 1997, p. 49.

93 Kraus, C.: "Avarice épistémique et économie de la connaissance: le pas rien du constructionnisme social", en Rouch et al. (eds.), op. cit., (pp. 39-59), p. 50.

94 Braidotti, R.: Transpositions, Cambridge, Polity Press, 2006, p. 141.

95 Braidotti, R.: Sujetos nómades. Corporización y diferencia sexual en la teoría feminista contemporánea, Buenos Aires, Paidós, 2000, p. 184.

96 Ibid., p. 195.
} 
- hay una alteridad que funciona en el nivel interior, plasmada en esa multiplicidad de elementos que confluyen en la formación-siempre inacababa- de la identidad individual: etnia, nivel educativo, estatus económico, etcétera.

- otro plano de alteridad viene dado por el encuentro con el otro. La identidad no es un proceso solipsista sino que se va configurando a partir de la relación con lo externo, con las cosas del mundo y, en general, con el Otro tomado en sentido amplio.

- un tercer plano de alteridad viene dado por la dimensión temporal. Desde esta perspectiva la identidad actual es el resultado de toda la secuencia de vivencias anteriores y de la impronta que han dejado en la memoria del individuo, etcétera. Para comprender cómo se articula este plano resulta muy útil la noción de 'identidad narrativa' desarrollada por Ricoeur, que explica la identidad individual como un relato que conecta distintas vivencias y hechos y les da sentido al insertarlos en una trama argumental que los abarca e integra.97

Recapitulando, la teoría feminista contemporánea insiste en que, en ese núcleo de alteridades que configuran la identidad irrepetible de cada individuo, el rasgo de ser hombre o mujer es un dato más, una incardinación cuyas particularidades merece la pena explorar -la reflexión sobre la maternidad es un buen ejemplo de esa exploración-, pero sin caer en definiciones esencialistas ni establecer jerarquías o dicotomías que desvaloricen lo femenino.

\section{Conclusiones}

La reflexión sobre la alteridad supone un intento de abordar la relación con el Otro sin cancelar su diferencia. A partir del análisis de esta noción filosófica se identifican claramente dos rasgos básicos que la caracterizan: la importancia del discurso, que se hace patente en la medida en que la alteridad se plasma lingüísticamente y se inscribe en el lenguaje; y la importancia de la acción, dado que la confrontación con la alteridad es el punto de partida del movimiento que me abre al otro y que, a la vez, me abre a mí mismo, porque conocerse a sí mismo y llegar a ser un 'yo' es un proceso de largo recorrido que pasa por relacionarse con el otro -esto se aprecia especialmente en la reflexión sobre la relación con la madre como primera alteridad por la que advienen todas las demás alteridades-.

El pensamiento contemporáneo de la alteridad, que ofrece nuevos contenidos a la metafísica, la ética o la filosofía política, puede enriquecerse con las aportaciones de la teoría feminista más reciente. Según este enfoque, es crucial superar las

97 "La operación narrativa implica un concepto totalmente original de identidad dinámica, que compagina las categorías de identidad y diversidad". Ricoeur, SM, p. 141. 
definiciones de la mujer como alteridad par excellance, que la sitúan en un esquema dual y jerarquizado inamovible, y bucear en las diferentes alternativas que se contraponen a ese inmovilismo y se esfuerzan en definir la alteridad sexual en términos más flexibles. En este sentido, resulta muy oportuna la reflexión sobre la maternidad como núcleo simbólico y la recuperación de la relación con la madre como modalidad complementaria de relación con la alteridad. Asimismo, estas consideraciones amplían los límites de la ética al incluir en su esfera normativa el principio del cuidado. Igualmente novedosa es la definición de la identidad sexual como un proceso abierto, no preestablecido, y que por lo tanto se presta a nuevas resignificaciones de lo que se entiende por 'masculino' y 'femenino'.

Si se asume desde el principio que las identidades no son algo monolítico, y que la propia definición de 'masculino' y 'femenino' es problemática e imposible de deslindar de todas las determinaciones históricas y culturales que se le han adherido a lo largo de los siglos, resultará más fácil cuestionar y superar los enfoques que esencializan la diferencia de género, y aproximarse a la alteridad sexual con una mirada más abarcadora. Considero que esa mirada crítica es la principal aportación que puede hacer la teoría feminista al concepto filosófico de alteridad y al pensamiento de la diferencia en general.

\section{Referencias bibliográficas}

Beauvoir, S. de: El segundo sexo. Vols. I y II, Madrid, Cátedra, 2002.

BenhabiB, S.: "Feminism and Postmodernism: an uneasy Alliance", en Benhabib,

Butler, Cornell y Fraser (eds.), Feminist contentions: a philosophical exchange,

New York y Londres, Routledge, 1995, pp. 17-34.

Bourgeouis, P.: "Ricoeur and Levinas: Solicitude in Reciprocity and Solitude in

Existence", en R. A. Cohen y J. L. Marsh (eds.), Ricoeur as another. The ethics of subjectivity, Albany, State University of New York Press, 2002, pp. 109-126.

Braidotti, R.: Metamorfosis. Hacia una teoría materialista del devenir, Madrid, Akal, 2005.

BRAIDOTTI, R.: Sujetos nómades. Corporización y diferencia sexual en la teoría feminista contemporánea, Buenos Aires, Paidós, 2000.

Braidotti, R.: Transpositions, Cambridge, Polity Press, 2006.

Buber, M.: Yo y tú, Madrid, Caparrós, 1995.

Butler, J.: Bodies that matter: On the discursive limits of 'sex', New York, Routledge, 1993.

ButLeR, J.: Excitable speech. A politics of the performative, New York, Routledge, 1997.

ButLer, J.: Gender trouble. Feminism and the subversion of identity, New York, Routledge, 1990. 
Cereceda, M.: El origen de la mujer sujeto, Madrid, Tecnos, 1997.

Dilthey, W.: "Ideas acerca de una psicología descriptiva y analítica", en E. Ímaz (coord.), Obras de Wilhem Dilthey VI. Psicología y Teoría del Conocimiento, México, Fondo de Cultura Económica, 1978.

FERnÁNDEZ Guerrero, O.: "Encuentros y desencuentros entre el feminismo y la maternidad", en G. Franco Rubio (ed.): Debates sobre la maternidad desde una perspectiva histórica (Siglos XVI-XX), Barcelona, Icaria, 2010, pp. 425-438.

Gilligan, C.: "Con otra voz: las concepciones femeninas del yo y de la moralidad", en López de la Vieja, Barrios, Figueruelo, Velayos y Carbajo (eds.), Bioética y feminismo. Estudios multidisciplinares de género, Salamanca, Universidad de Salamanca, 2006, pp. 15-56.

IrIGARAY, L.: Ce sexe qui n'en est pas un, Paris, Éditions de Minuit, 1977.

IRIGARAY, L.: Yo, tú, nosotras, Madrid, Cátedra, 1992.

Kraus, C.: "Avarice épistémique et économie de la connaissance: le pas rien du constructionnisme social", en Rouch, Dorlin y Fougeyrollas-Schwebel (coords.), Le corps, entre sexe et genre, Paris, L'Harmattan, 2005, pp. 39-59.

Levinas, E.: Totalidad e infinito. Ensayo sobre la exterioridad, Salamanca, Sígueme, 1999.

Muraro, L.: El orden simbólico de la madre, Madrid, Horas y horas, 1994.

PALACIO, M.: La mujer y lo femenino en el pensamiento de Emmanuel Levinas. Un debate de género en torno a la alteridad femenina, Córdoba (Argentina), Universidad Católica de Córdoba, 2008.

Pateman, C.: El contrato sexual, Barcelona, Anthropos, 1995.

Quesada Talavera, B.: “Aproximación al concepto de 'alteridad' en Lévinas. Propedéutica de una nueva ética como filosofía primera", Investigaciones fenomenológicas, vol. 3 monográfico Fenomenología y política, 2011, pp. 393-405. $<$ http://www.uned.es/dpto_fim/invfen/Inv_Fen_Extra_3/25_QUESADA.pdf $>$ [Consulta: 12 jul. 2011].

Reyes Pedraza, J.: “La alteridad en Emmanuel Levinas", en J. Martínez Contreras y L. Ponce de León (coords.), El saber filosófico. Sociedad y ciencia, México, Siglo XXI, 2007, pp. 159-167.

Rich, A.: Nacemos de mujer. La maternidad como experiencia e institución, Madrid, Cátedra, 1996.

Ricoeur, P.: Finitud y culpabilidad, Madrid, Taurus, 1982.

Ricoeur, P.: Sí mismo como otro, Madrid, Siglo XXI, 1996.

Rouch, H.: "La gestation, paradoxe immunologique de la dualité", en Rouch,

Dorlin y Fougeyrollas-Schwebel (coords.), Le corps, entre sexe et genre, Paris, L'Harmattan, 2005, pp. 105-126.

RuDDICK, S.: Maternal thinking. Towards a Politics of Peace, London, Wordsworth, 1990. 
SARTRE, J.-P.: El ser y la nada, Madrid, Alianza, 1984.

TOMASSI, W.: Filósofos y mujeres, Madrid, Narcea, 2002.

VAlCÁRCEL, A.: La política de las mujeres, Madrid, Cátedra, 1994.

VillarmeA, S.: "The provocation of E. Levinas for feminism", The European Journal of Women's Studies, 6.3, 1999, pp. 291-304.

Olaya Fernández Guerrero

Doctora en Filosofía

UNED Centro Asociado de La Rioja

olayafg@yahoo.es 